\title{
FORMAÇÃO DOCENTE E ENSINO DE HISTÓRIA: VIOLÊNCIA CONTRA AS MULHERES E SUA LUTA POR DIREITOS COMO TEMA DE EXPERIÊNCIA DIDÁTICO-PEDAGÓGICA EM SALA DE AULA
}

\author{
Edna Maria Matos Antonio \\ Universidade Federal de Sergipe (UFS), Brasil \\ E-mail: ednamatos.antonio@gmail.com \\ ORCID: https://orcid.org/0000-0001-6748-9312 \\ Fernanda Carolina Pereira dos Santos \\ Universidade Federal de Sergipe (UFS), Brasil \\ E-mail: nanda.carolina01@gmail.com \\ ORCID: https://orcid.org/0000-0003-0053-8524
}

Data de recebimento: $14 / 01 / 2020$

Data de aprovação: $31 / 03 / 2020$

DOI: https://doi.org/10.30612/frh.v22i39.12574

\begin{abstract}
Resumo: $\mathrm{O}$ artigo apresenta o resultado de experiência pedagógica que buscou problematizar a imagem e a percepção social feminina em diferentes contextos geográficos e históricos. As atividades desenvolvidas em aulas de História, dialogando com vivências dos estudantes e com problemas sociais atuais relativos às mulheres, proporcionaram e validaram dimensão práticoreflexiva à disciplina História. Para tanto, abordou-se a atuação histórica de algumas mulheres articulada ao conteúdo curricular obrigatório, valorizando o debate sobre a diversidade social, racial e cultural, e se subsidiou a metodologia de ensino e seus fundamentos com conhecimento teórico-bibliográfico. A atividade foi guiada pela necessidade de problematizar questões contemporâneas, como a violência contra as mulheres e sua luta por direitos, com enraizamento histórico. As reflexões realizadas destacam a relevância do Programa Institucional de Bolsas de Iniciação à Docência (PIBID) para a formação docente, por ensejar experiências pedagógicas na constituição de saberes e no planejamento pedagógico pautado na clareza de objetivos.
\end{abstract}

Palavras-Chave: Ensino de História. Formação Docente. Direitos das Mulheres. PIBID.

\section{TEACHING TRAINING AND HISTORY TEACHING: VIOLENCE AGAINST WOMEN AND THEIR FIGHT FOR RIGHTS AS A THEME OF TEACHING PEDAGOGICAL EXPERIENCE IN THE CLASSROOM}

\begin{abstract}
The article presents the result of a pedagogical experience that sought to problematize the image and the perception of women in different geographical and historical contexts. The activities developed in History classes, dialoguing with students' experiences and with current social problems related to women, provided and validated practical-reflective dimension to History discipline. For this purpose, approach was made to the historical performance of some women inserted in the mandatory curriculum content, valuing social, racial and cultural diversity, and support to the teaching methodology and its foundations was given through
\end{abstract}


theoretical-bibliographic knowledge. The activity was guided by the need to problematize contemporary issues, such as violence against women and their fight for rights, within historical roots. The reflections carried the relevance of the Institutional Program for Teaching Initiation Scholarships (PIBID) for teacher training, for giving pedagogical experiences in the constitution of knowledges and in pedagogical planning ruled by clarity of objectives.

Keywords: History Teaching. Teacher Training. Women's Rights. PIBID.

\section{FORMACIÓN DOCENTE Y ENSEÑANZA DE HISTORIA: VIOLENCIA CONTRA LAS MUJERES Y SU LUCHA POR LOS DERECHOS COMO TEMA DE LA EXPERIENCIA DIDÁCTICA-PEDAGÓGICA EN CLASSE}

Resumen: El artículo presenta el resultado de una experiencia pedagógica que buscó problematizar la imagen y la percepción de las mujeres en diferentes contextos geográficos e históricos. Las actividades desarrolladas en clases de Historia, dialogando con experiencias de los estudiantes y con problemas sociales actuales relacionados con la mujer, proporcionaron y validaron dimensión práctico-reflexiva a la disciplina Historia. Para este propósito, se ha abordado el desempeño histórico de algunas mujeres insertado en el contenido curricular obligatorio, valorando la diversidad social, racial y cultural, y se ha apoyado la metodología de enseñanza y sus fundamentos en conocimiento teórico-bibliográfico. La actividad fue guiada por la necesidad de problematizar temas contemporáneos, como la violencia contra las mujeres e su lucha por derechos, em raíces históricas. Las reflexiones realizadas resaltan la relevancia del Programa Institucional de Becas de Iniciación Docente (PIBID) para la formación docente, por brindar ocasión a experiencias pedagógicas en la constitución de conocimientos y en la planificación pedagógica gobernada por claridad de objectivos.

Palabras Clave: Enseñanza de Historia. Formación Docente. Derechos de las Mujeres. PIBID.

\section{Introdução}

O processo educacional, como se apresenta hoje, valorizado por ter fundamental importância para a construção de uma sociedada mais justa e cidadã, é constituído por embates que envolvem importantes desafios de caráter epistemológico e político, bem como pela presença de tensões no que tange à realização de efetivo diálogo entre teoria e prática. Da formação docente, o "fazer-se professor", até a experiência pedagógica no ambiente escolar, o famoso "chão da escola", o professor é instigado, com seu conhecimento, seu compromisso com a transformação da realidade social e sua atitude, a desenvolver práticas que resultem em conhecimento significativo para o aluno, que, em sua individualidade, agrega um mundo de situações e realidades socioeducacionais. É nesse cenário complexo que o conhecimento e sua função social se apresentam como ferramentas de transformação de uma sociedade, não apenas 
pela função inerente, mas por ser capaz de fornecer repertório informativo e crítico para tratar de problemas recorrentes do cotidiano e do mundo social com todas as suas complexidades.

Assim, entende-se a escola como matriz e reflexo de tensões que exemplifica e sintetiza os dilemas do tecido social e as questões de seu tempo. É instituição social inserida numa cultura, numa estrutura econômica, que produz e reproduz os valores vigentes na sociedade, propagando-os e mesmo consolidando estereótipos discriminatórios, discursos hieraquizadores, preconceitos e, muitas vezes, reiterando os vetores ideológicos que conformam as desigualdades sociais e as formas de exclusão. Da mesma forma, pensa-se que ela seja também potencialmente capaz de atuar no sentido de moldar concepções e atitudes mais permeáveis aos valores de respeito à diferença, ao direito à vida de importantes segmentos e grupos sociais, à democracia e à convivênvia cidadã.

Por buscar a compreensão das raízes profundas e dos ritmos da evolução das questões sociais ao longo do tempo e sua presentificação na comteporaneidade, a História, na dupla condicão de saber e disciplina curricular, não poderia ficar indiferente aos movimentos e tensões que acompanham a sociedade e sua dinâmica educacional. Longe de afirmar que cabe apenas às ciências humanas tratar da questão ou, em seu extremo, negar a capacidade de esse saber compreender uma realidade social, pelo contrário, nota-se que as diversas disciplinas das chamadas ciências exatas e da natureza, vistas como instâncias plenas de objetividade e neutralidade por força da primazia de discurso científico tecnologizante, promovem também discursos que podem ser discriminátorios de gênero e de identidade e têm responsabilidade social por comportamentos e visões de mundo excludentes. Contudo, ante a complexidade dos problemas sociais em nosso país, as ciências humanas se consolidam como conjunto importante de conhecimento e proposições de intervenção nessa realidade.

No Brasil, coube aos movimentos sociais, em sua pluralidade de identidades (indígenas, negros, quilombolas, feministas e LGBTQI, entre outras) e reivindicações, serem os principais agentes impulsores do reconhecimento de direitos e da diversidade, bem como de sua discussão na pauta social e política. Elemento importante nas demandas desses movimentos foi (e vem sendo) questionar como a mídia, a escola, o Estado e as políticas públicas tratam a diversidade em suas variadas manifestações, exigindo respostas e reações ao reconhecimento de direitos. Nesse sentido, interessa, na discussão aqui apresentada, contribuir para evidenciar o papel da escola, em seus diferentes níveis e modalidades, como importante instância geradora de experiências que promovam saberes, sensibilidades e subjetividades em torno da questão, entre tantos temas sensíveis, do direito das mulheres à vida sem violência. Para a consecução desse 
Formação Docente e Ensino de História: violência contra as mulheres e sua luta por direitos como tema de experiência didático-pedagógica em sala de aula - Edna Maria Matos Antonio; Fernanda Carolina Pereira dos Santos

objetivo, fez-se uso da análise de experiência pedagógica praticada pelo PIBID/História da Universidade Federal de Sergipe em turma de sexto ano do ensino fundamental de escola pública na cidade de São Cristóvão, região metropolitana de Aracaju.

O Programa de Iniciação à Docência - PIBID ${ }^{1}$ - visa incentivar a formação de docentes em nível superior para atuar na Educação Básica, proporcionando situações de experiência didática de caráter enriquecedor e criativo que auxiliem no aperfeiçoamento de sua preparação profissional, de forma diferenciada e complementar ao que é ministrado na Universidade. Sua meta é promover a interação real entre Educação Superior e Básica, na qual, espera-se, diálogo instigador, uma vez que o conhecimento/reflexão da realidade educacional repercute no planejamento pedagógico que orienta a formulação dos currículos e diretrizes de docência dos cursos de Licenciatura. A percepção proporcionada pela vivência da realidade escolar, problematizando a diferença entre teoria e prática e entre currículo e sala de aula e propondo e experimentando estratégias didáticas, com seus erros e acertos, agrega excepcional valor pedagógico e social ao projeto.

Outro aspecto a ser valorizado pela experiência do PIBID diz respeito ao retorno de reflexões e informações oriundas das experiências pedagógicas da sala de aula para a universidade e políticas educacionais. $\mathrm{O}$ olhar e a vivência dos bolsistas nas escolas tocam diretamente antigo problema: a distância entre o que se produz na academia e sua absorção pela Educação Básica, em que muitas vezes os conteúdos aprendidos nos cursos superiores são ensinados com pouca relação com a realidade escola ou com pouco significado para o aluno. A elaboração crítica de estratégias didáticas para o tratamento de conteúdos de História que constam na grade curricular do curso de graduação pôde ser experimentada no processo de formação docente, fazendo com que se percebesse, ainda, que os saberes também são produto da própria experiência de ensinar.

Essa constatação se aproxima de Tardif (2002, p. 19), que aponta que o saber profissional se dá na confluência de vários saberes oriundos da sociedade, da instituição escolar, dos outros atores educacionais, das universidades. Assim, num país como o Brasil, em que a violência contra a mulher, culturalmente construída a ponto de se naturalizar, alcança índices alarmantes, é legitimo perguntar como a escola tem abordado a questão em suas experiências educativas e de socialização de jovens numa fase especialmente importante para a construção de dogmas .

1 Iniciativa política de formação inicial de docentes, visando elevar os índices educacionais, o PIBID, criado pelo Decreto n. 7.219/2010 (BRASIL, 2010) e regulamentado pela Portaria 096/2013 (BRASIL, 2013), é coordenado pela CAPES (Coordenação de Aperfeiçoamento de Pessoal de Nível Superior), agência ligada ao Ministério da Ciência e Tecnologia. 
Formação Docente e Ensino de História: violência contra as mulheres e sua luta por direitos como tema de experiência didático-pedagógica em sala de aula - Edna Maria Matos Antonio; Fernanda Carolina Pereira dos Santos

\section{Educação para as relações de gênero}

Na sociedade brasileira, o processo de construção social da violência contra as mulheres é problema público, de raízes históricas, que persiste em meio a várias questões socioculturais também graves e preocupantes. Trata-se de enfrentar tipo específico de violência que desconhece barreiras sociais ou de nível de escolarização, mas encontra na população pobre sua manifestação mais perversa. Segundo o Atlas da Violência 2019, produzido pelo Instituto de Pesquisa Econômica Aplicada e pelo Fórum Brasileiro de Segurança Pública (IPEA; FBSP, 2019), o número de femicídios no Brasil entre 2007 e 2017 cresceu 30,7\%. O Estado de Sergipe teve o terceiro maior crescimento, com taxa de 107\%. Segundo o Anuário Brasileiro de Segurança Pública 2019 (FBSP, 2019), nas ocorrências e boletins registrados em 2018, 53 mulheres foram assassinadas na zona metropolitana de Aracaju, capital do Estado, 5.121 sofreram violência doméstica e 542 foram estupradas ou sofreram tentativa. Os números mostram realidade cruel, mas mascaram vários outros casos não denunciados.

Para tratamento da questão, é importante aludir à perspectiva conceitual de gênero, que, no entanto, não deve ser entendido como sinônimo de mulher ${ }^{2}$. Ainda que complexo, pode ser compreendido como conjunto de sentidos atribuídos a corpos e identidades/subjetividades, e, por extensão, a objetos, espaços e práticas materiais e simbólicas, denominados femininos ou masculinos, de forma dicotômica e hierárquica (CARVALHO et al., 2017, p. 55). Elemento constitutivo de relações sociais e de poder, é fundado sobre o conjunto de características e diferenças percebidas entre os sexos (SCOTT, 1995, p. 85).

A discriminação e inferiorização das mulheres e a detenção de poderes/privilégios pelos homens, bem como a naturalização dessa realidade, são apenas facetas circunscritas em seu conceito e devem ser entendidas enquanto construção social. Nesse aspecto, devem-se destacar, como artífices dessa realidade, as esferas religiosas, política, jurídica e educativa. A escola, como espaço construtor de relações de gênero, precisa debater essas questões, uma vez que o gênero, enquanto construção social do feminino e do masculino e elemento das relações sociais,

$2 \quad$ Adotar conceito de gênero implica reconhecer seu caráter fluído e disputado na agenda política dos grupos feministas, polêmica na academia e marcada por amplo debate. O uso da palavra gênero demarca a diferença no comportamento de homens e mulheres enquanto construção cultural. Seu uso está imerso na construção de lentes analíticas que procuravam incluir e demarcar a identidade feminina em contexto centrado no homem. A categoria "mulher" foi substituída posteriormente por "mulheres", buscando destacar as várias realidades sociais, culturais e econômicas que demarcam a pluralidade de formas de ser mulher ao longo da história e dentro de temporalidade específica. Ademais, foi incluída a categoria de análise "gênero" que permitiu a compreensão das relações entre homens e mulheres, bem como o relacionamento e os comportamentos que foram construídos culturalmente e normatizados enquanto comportamentos de mulheres e de homens. Ver: PEDRO, 2011, 2005. 
Formação Docente e Ensino de História: violência contra as mulheres e sua luta por direitos como tema de experiência didático-pedagógica em sala de aula - Edna Maria Matos Antonio; Fernanda Carolina Pereira dos Santos

surge como voz silenciada na sociedade e particularmente na escola. Mas como fazer? A simples apresentação de conceitos não resolve o problema e não é suficiente para provocar reflexão. A abordagem precisa suscitar subjetividades e emergir como problema que integra o cotidiano dos alunos.

As questões de gênero no sistema educacional brasileiro são abordadas em alguns materiais de apoio pedagógico elaborados para orientar os docentes no trato das temáticas e na construção de projetos educacionais. Destaca-se o volume 10.5 dos PCNs - Parâmetros Curriculares Nacioniais: temas transversais/orientação sexual (BRASIL, 1998), que, produzido em contexto de importantes inovações e projeções progressistas para o sistema educacional brasileiro, sugere que a discussão seja trazida para a sala de aula por meio de temáticas relacionadas à equidade entre os sexos, à flexibilização dos padrões de comportamento, ao questionamento das esteriotípias e à violência ligadas ao gênero. Dessa forma, o trabalho em sala de aula deve ser alicerçado no propósito de combater relações autoritárias, questionar a rigidez dos padrões de conduta estabelecidos para homens e mulheres e apontar caminhos para sua transformação.

Motivados por essa questão e seguindo essas orientações, o projeto intitulado "Mulheres, violência e direitos humanos: a intersecção da função feminina no Egito, Grécia e contemporaneidade" surgiu com a preocupação de trabalhar os direitos humanos com base no conhecimento e reconhecimento das variadas lutas femininas e formas de ser mulher ao longo da história $^{3}$. Seu objetivo foi problematizar a imagem e a construção do feminino em diferentes contextos geográficos e históricos, para dotar de historicidade a reflexão em torno dos papeis sexuais, atribuídos ou efetivos, que envolveram a atuação social das mulheres numa temporalidade

Para a execução do projeto foi necessário construir entre os alunos a noção de que as mulheres, por muitas décadas, foram excluídas e ignoradas pela história. Esse apagamento da presença feminina não se explica por questões de participação - não tão escassa assim como nos mostra a própria história -, mas por bem articulada operação de invisibilização, que, por sua vez, é reflexo de enraizadas relações de poder sexistas, de submissão e de discriminação por gênero. $\mathrm{Na}$ história econômica, por exemplo, eram consideradas improdutivas e, ao se estudar a

\footnotetext{
3 As atividades foram desenvolvidas no período de abril a dezembro de 2017, seguindo o eixo temático "Direitos Humanos na escola: história, reflexão e ação", sob a orientação da Prof. Dra. Edna Maria Matos Antônio e supervisão do Prof. Msc. Eduardo Lopes Teles, no Colégio Estadual Armindo Guaraná, São Cristóvão/SE, na turma do $6^{\circ}$ ano $\mathrm{D}$, com 25 alunos de faixa etária entre 11 e 15 anos. O grupo de alunas de licenciatura em História foi formado pelas discentes Fernanda Carolina Pereira dos Santos, Yone Santos Andrade e Luciana Alves Santos.
} 
Formação Docente e Ensino de História: violência contra as mulheres e sua luta por direitos como tema de experiência didático-pedagógica em sala de aula - Edna Maria Matos Antonio; Fernanda Carolina Pereira dos Santos

sociedade, focalizavam-se as classes e se neglicenciavam os sexos e, na história cultural, priorizava-se a ação masculina em geral. O sexo feminino "alimentava as crônicas da 'pequena' história, meras coadjuvantes", e, quando apareciam, estavam associadas a modelo de ser mulher com função social bem definidade e demarcada: a maternidade (PERROT, 1988, p. 185), ou, na melhor das hipóteses, com protagonismo político marcado por características masculinizantes.

Apesar dos avanços epitesmológicos, expansão de direitos e atuação política, esse modelo tradicional de identificar a presença feminina permanece nos livros didáticos de História e nas salas de aula. Segundo Silva (2007, p. 228), as mulheres são abordadas nos manuais em boxes que abrem pequenos parênteses para que as relações de gênero sejam abordadas. No entanto, suas reflexões, ainda que inovadoras, não rompem com o senso comum e trazem representações da virilidade e da dominação masculina em detrimento da fragilidade e submissão feminina. As variadas nuances e construções sociais do feminino se tornaram palco dos discursos historiográficos e precisam ser debatidos em sala de aula, uma vez que o livro didático, muitas vezes o único suporte didático à disposição do professor e professora, e as relações escolares corroboram a construção androcêntrica e sexista (BOTÃO et al., 2010).

Além disso, foi muito pertinente discutir essa temática em sala de aula valorizando a aferição de saberes proporcionada pelo diálogo entre prática e teoria. Assim, para planejamento do projeto, adotou-se o conceito Tema Gerador, do educador Paulo Freire (2005), que proporcionou reflexão consistente por destacar a produção de novo conhecimento a partir da formação humana. Para o autor, referência pedagógica incontornável pela proposta revolucionária de compreender o processo de aprendizagem, a educação humanizadora requer cutivar o conhecimento de forma interdisciplinar, articulando dialeticamente experiências de vida com sistematização rigorosa e crítica do saber.

Com base nos ensinamentos de Paulo Freire e na observação da realidade escolar do campo de atuação, foi elaborada proposta que abordasse problemática atual com vista a sua compreensão em perspectiva histórica e que adotasse a reflexão promovida por essa experiência como subsídio para a mudança de comportamento. Dessa forma, foi pensado projeto que dialogasse com três realidades históricas distintas: egípcia, ateniense e brasileira, de maneira que as historicidades analisadas ajudassem a refletir sobre o fenômeno da violência contra a mulher, que persiste atualmente. O reconhecimento das especicificades temporais e culturais foi utilizado como estratégia metodológica para auxiliar na problematização da questão, evidenciando a permanência de tratamento subalternizante das mulheres. Por meio do diálogo entre o papel desempenhado pelas mulheres atenienses e egípcias foram instigadas as várias formas de ser 
mulher e as suas funções sociais históricas. Era esperado que as aulas contribuíssem para a formação de concepção histórica pelos alunos, sob prisma transversal e horizontal, como nos ensina Rüsen:

O corte transversal revela o saber histórico como síntese da experiência como interpretação. Com isso, a diversidade e a correlação dessas duas dimensões articuladas com a terceira, a dimensão de orientação da vida prática, de modo a deixar claro que e quando o pensamento histórico, especificamente científico, surte efeitos práticos. $\mathrm{O}$ corte horizontal trata da formação como processo de socialização e de individualização, trata da dinâmica evolutiva interna da formação da identidade histórica e, naturalmente também, se e como essa dinâmica pode e deve ser influenciada pela ciência. (RÜSEN, 2007, p. 87-88).

Dessa forma, as aulas foram planejadas de maneira a despertar o interesse dos discentes, aproximando o conteúdo programático do cotidiano vivenciado por eles. Com auxílio das mídias digitais composta por imagens, músicas e vídeos, foi feita a aproximação com o conhecimento das experiências históricas da Grécia e do Egito antigos, objetivando refletir as várias funções e presenças femininas nos respectivos cortes temporais. $\mathrm{Na}$ tessitura desse debate, a todo momento, foram rememoradas frases e ações atuais que discriminam e colocam a mulher em situação de subserviência, contrastando com a diversidade e a pluralidade da experiência histórica feminina. Posteriormente, foi escolhida Alerquina, personagem dos HQs, dos filmes e dos desenhos animados da DC Comics, para debater as funções sociais da mulher contemporânea e os tipos de violência a que está sujeita na sociedade.

Por meio dessa reflexão e objetivando contribuir para a construção de consciência histórica (RÜSEN, 2007), buscou-se a articulação entre o contéudo e as vivências do cotidiano dos discentes (GIMENO SACRISTÁN, 1999), ao discutir a representação da mulher contemporânea, para que constatassem existir ainda, apesar dos inúmeros avanços conquistados pelas mulheres, grande discrepância social e econômica entre os gêneros, ficando as mulheres sujeitas a diversas formas de violência e negação de direitos básicos.

Ao se formular a proposta didática, atentou-se para a problemática do anacronismo. Entretanto, deve-se destacar que, em todas as realidades trabalhadas, foi necessária cuidadosa seleção bibliográfica, para que a problematização em torno das mulheres fosse apresentada de forma adequada no contexto histórico abordado. A comunicação entre os tempos, notadamente a vinculação do presente de quem vive ao passado, que é objeto, operação intelectual distintiva do oficio do historiador, ajuda a dar sentido para o conhecimento histórico e seus usos. Como sublinha José Carlos Reis (1999, p. 9), “toda interpretação, que é uma atribuição de sentido ao 
Formação Docente e Ensino de História: violência contra as mulheres e sua luta por direitos como tema de experiência didático-pedagógica em sala de aula - Edna Maria Matos Antonio; Fernanda Carolina Pereira dos Santos

vivido, se assenta sobre um "mirante temporal", um ponto de vista, em um presente - vê-se a partir de um lugar social e um tempo específicos.

Ademais, a correlação entre os contéudos estudados e a realidade vivida, é chamada de acronia, auxílio pedagógico "utilizado nas construções elaboradas para as aulas do ensino de história, nas quais professores criam construções originais para tornar possível a atribuição de sentido pelos alunos aos temas estudados" (MONTEIRO, 2012).

Assim, conforme debate tecido por Ana Maria Monteiro (2012), o projeto valeu-se do uso de heterocronias, "mescla do tempo escolar com o tempo histórico presente e passado". Convém destacar que os assuntos da Grécia e do Egito antigos, conteúdos curriculares obrigatórios em turmas de sexto ano do ensino fundamental, foram articulados em diferentes regimes de historicidade com o presentismo e debate muito caro: a violência contra a mulher.

O eixo norteador da discussão foi o respeito ao direito universal feminino a viver com dignidade, igualdade e livre da violência de gênero e doméstica, que, ainda no século XXI, é das violações de direito mais toleradas no mundo e que faz vítimas principalmente nas camadas menos favorecidas economicamente e de menor escolaridade. A discussão do tema em sala de aula se faz urgente, uma vez que o Brasil, sem referir outros indicadores com índices inaceitáveis, ocupa, de acordo com os dados da ONU Mulheres (2016), entidade das Nações Unidas pela Igualdade de Gênero e o Empoderamento das Mulheres, a quinta posição no ranking de países que mais praticam o feminicídio ${ }^{4}$.

A variedade de metodologias de ensino empregadas tem sua razão principal no fato das bolsistas terem buscado ludicizar a abordagem desses conteúdos na sala de aula. Durante o planejameno, considerou-se o modelo proposto por Fernando Hernández e Montserrat Ventura (1988) que pressupõe dever o/a docente abandonar o papel de "transmissor de contéudos" para se transformar em pesquisador, e o/a aluno/a, por sua vez, passar de receptor passivo a sujeito dos processos de ensino e de aprendizagem. O apoio da professora coordenadora do curso de licencitura da Universidade e do supervisor (professor de História das turmas na escola), com pontuais comentários, sugestões e direcionamento, foi fundamental para a efetivação das atividades.

\section{Relato da experiência didático-pedagógica}

\footnotetext{
$4 \quad$ O conceito de feminicídio foi formulado em 1970, por Diana Russel e compreende "las formas de asesinato sexista, es decir, los asesinatos realizados por varones motivados por un sentido de tener derecho a ello o superioridad sobre las mujeres, por placer o deseos sádicos hacía ellas, o por la suposición de propiedad sobre las mujeres" (ONU MUJERES, 2014).
} 
Formação Docente e Ensino de História: violência contra as mulheres e sua luta por direitos como tema de experiência didático-pedagógica em sala de aula - Edna Maria Matos Antonio; Fernanda Carolina Pereira dos Santos

Nas aulas iniciais, as bolsistas apresentaram o projeto à turma, explicando a dinâmica que iria ser empregada. Posteriormente, foi aplicado questionário para averiguar a visão dos estudantes sobre os tipos de violência que marcam o cotidiano de nossa sociedade a partir de suas próprias concepções para que as bolsistas elaborassem a abordagem dos conteúdos nas aulas seguintes. Por fim, por intermédio de adaptação de dinâmica proposta por Botão et al. (2010), foram lançadas algumas perguntas provocativas: “o que é ser homem?”; “o que é ser mulher?”; "como as crianças aprendem como deve ser o comportamento de uma mulher ou de um homem?”; “em quais lugares e espaços sociais estão as mulheres e os homens?”; "em que situações uma adolescente ou jovem se sente discriminada pelo fato de ser mulher"; "em que situações um adolescente ou jovem se sente discriminado pelo fato de ser homem?".

Com a resposta a essas questões, foi produzido quadro comparativo para refletir sobre a posição/condição da mulher e do homem na sociedade brasileira atual. Para arrematar o encontro, foram lidas algumas frases utilizadas no dia a dia para depreciar a mulher, tendo sua interpretação suscitado debate na turma.

$\mathrm{Na}$ terceira e quarta aulas, foi distribuída cópia da letra de "Mulheres de Atenas", de Chico Buarque, e, em seguida, exibido vídeo da banda Mulheres de Hollanda interpretando essa canção. No segundo momento, por meio de questões que conduziram ao debate, conversou-se sobre os tipos de mulher existentes na sociedade ateniense e retratadas na música, e as funções por elas desempenhadas. Posteriormente, por meio de quatro imagens que ilustram as mulheres de Atenas, foi analisado o papel das camponesas, das prostitutas e das servas, problematizando as noções de maternidade e de subserviência.

No quinto encontro, a aula teve por recurso a música "100\% feminista", de Mc Carol e Karol Conka, que permitiu à sala conhecer e explorar a biografia de algumas mulheres citadas na música, como Carolina de Jesus ${ }^{5}$, Chica da Silva ${ }^{6}$ e Dandara ${ }^{7}$. Por meio da contextualização

\footnotetext{
5 Carolina Maria de Jesus, ou Bitita, nasceu em 14 de março de 1914 em terras mineiras. Em São Paulo, adulta, morava com seus três filhos em barraco na favela do Canindé. Registrou, em mais de 4.500 páginas manuscritas, organizadas em 37 cadernos, a rotina desgastante de catadora de papel lidando com racismo, machismo, exclusão social e a fome. Ver: CASTRO; MACHADO, 2007.

6

Francisca da Silva Oliveira, ou Chica da Silva, passou sua adolescência no Tejuco, Minas Gerais, como escrava doméstica de Manuel Pires de Sardinha, tendo como ele seu primeiro filho. Alforriada em 1754, relacionou-se com João Fernandes de Oliveira, contratador de diamantes, tendo com ele grande prole. Ao final da vida era uma senhora abastada, proprietária de sobrados, joias, roupas finas e uma numerosa escravaria. Ver: FURTADO, 2003.

7 Dandara é figura enigmática. De sua história, sabe-se muito pouco, devido à (quase) ausência de vestígios documentais. Grande parte de sua história é baseada em relatos populares. Entretanto, sabe-se que ela viveu, desde nova, no quilombo dos Palmares, um dos maiores focos de resistência escrava do período colonial, localizado na serra da Barriga, atualmente Alagoas. Esposa de Zumbi, liderou a seu lado o quilombo nos anos finais. Ver: ARRAES, 2015.
} 
Formação Docente e Ensino de História: violência contra as mulheres e sua luta por direitos como tema de experiência didático-pedagógica em sala de aula - Edna Maria Matos Antonio; Fernanda Carolina Pereira dos Santos

histórica dessas agentes, examinou-se o protagonismo feminino de mulheres negras, pobres e da periferia, sua luta cotidiana e os desafios travados diariamente para a sobrevivência, além de sua sujeição à violência doméstica. A atividade proposta dialogou com o conceito de interseccionalidade, visto enquanto lente analítica sobre a interação estrutural das avenidas identitárias promotoras de barreiras raciais e sexistas (AKOTIRENE, 2018, p. 59).

$\mathrm{Na}$ sexta e sétima aulas, foram abordadas as biografias de duas personalidades femininas do Egito antigo: Cleópatra e Hathsepsut, complementadas por poema de amor intitulado "Conversas na Corte" (PEREIRA, 1998). Por meio da narrativa da vida das duas mulheres faraós e do fragmento literário, abordou-se a importância da mulher naquela sociedade e a posição de líder desempenhada. Ao final, foi pedido que os/as alunos/as elencassem os principais papeis da mulher na sociedade atual e pensassem em estereótipos profissionais ligados a gênero e na existência de alguma profissão que o sexo feminino não pudesse desempenhar, justificando sua indicação.

A oitava aula do projeto foi iniciada com a pergunta "o que é violência?", retomando a discussão inicial para, a partir desse ponto, discutirem-se as variadas facetas que a violência pode assumir numa relação de gênero. Com a ajuda de gráfico no formato de iceberg, foi desnaturalizada a noção que os alunos tinham de que a violência é apenas composta das formas visíveis, como violação, agressão física e assassinato. Explicou-se que a violência também abrange formas invisíveis, como invisibilização, humilhação, desvalorização, chantagem emocional, linguagem sexista e insultos. Ao final, por meio de exemplos do cotidiano, tratou-se de como essas formas de violência se reproduzem no dia a dia e no ambiente escolar.

$\mathrm{Na}$ nona e décima aulas, as bolsistas retomaram conceitos formulados anteriormente e apresentaram à turma as personagens Alerquina e Coringa, com objetivo de tematizar o relacionamento abusivo, problematizando as variadas formas de violência a que as mulheres podem ser submetidas. Em seguida, debateu-se a temática do assédio sexual na rua e no transporte coletivo, identificando essas práticas como forma de violência e não como comportamento comum. Além disso, apresentaram-se os dados de violência contra a mulher no Brasil, breves reportagens sobre a temática veiculadas nos jornais, finalizando com orientação sobre como realizar denúncia em casos de violências contra a mulher.

Importante frisar que a sequência didática apresentada foi construída por meio do diálogo com a turma, sendo necessário, portanto, pontuar esse processo. O primeiro contato com a turma não teve recepção positiva por parte dos discentes, uma vez que estavam acostumados com o marasmo escolar e não se sentiam confortáveis com as ações propostas. No decorrer do 
Formação Docente e Ensino de História: violência contra as mulheres e sua luta por direitos como tema de experiência didático-pedagógica em sala de aula - Edna Maria Matos Antonio; Fernanda Carolina Pereira dos

Santos

projeto, foram encontradas dificuldades como conversas paralelas e recusa em participar das atividades. Esses comportamentos inicialmente causaram frustração nas bolsistas, que, após a dinâmica da aula inaugural, perceberam que seria necessária a readequação das metodologias para despertar o interesse dos discentes.

Por meio de autocrítica, análise e conversa com a turma, percebeu-se que seria preciso responder a indagação: “porque e para que estudar história?”. Os alunos não se identificavam com os conteúdos curriculares obrigatórios tradicionais, no caso a Grécia e o Egito antigos. Os assuntos trabalhados estavam muito distantes de sua realidade, mesmo com o resgate histórico das mulheres. É preciso pontuar que os discentes frequentavam escola localizada ao lado da Universidade, entretanto não tinham a menor pretensão de continuar os estudos. Não era desinteresse o que estava em questão, era desigualdade: constatação de realidade que os empurraria para o mundo de trabalho com urgência para ajudar no sustento familiar. Nesse contexto, qual o sentido de conhecimento escolar tão distante da realidade vivida? Era necessário replanejamento.

O cronograma foi totalmente alterado. Levaram-se em consideração os gostos musicais dos alunos, com a inserção do funk e do rap, bem como a apresentação de mulheres que vivenciaram desigualdades estruturais e estiveram mais próximas da sociedade e visão de mundo em que estavam inseridos. Por mais que se saiba claramente que as realidades históricas são particulares, os alunos trazem para a sala de aula sua experiência de vida e precisavam se reconhecer nos debates travados, sobretudo como sujeitos históricos partícipes da construção do mundo em que vivem. A adequação do projeto ao cotidiano dos discentes foi um dos grandes desafios enfrentados na realização das atividades que, ao final, promoveu o envolvimento nas propostas, abraços de despedida e saudade.

\section{O chão da escola e uma conclusão}

O Programa Institucional de Iniciação à Docência - PIBID tem como meta promover condições de melhor formação docente, uma vez que possibilita aliar a prática à teoria estudada na licenciatura em História na Universidade Federal de Sergipe através da imersão do estudante na realidade escolar já em seu processo de construção profissional e política. Durante os meses de atividades no Colégio Estadual Armindo Guaraná, entre aplicação do projeto e observação do dia a dia escolar, foi possível ter melhor percepção da realidade de uma escola pública periférica e os desafios para o ensino de História. Essa experiência foi enriquecedora para a formação 
Formação Docente e Ensino de História: violência contra as mulheres e sua luta por direitos como tema de experiência didático-pedagógica em sala de aula - Edna Maria Matos Antonio; Fernanda Carolina Pereira dos Santos

pessoal e profissional dos licenciandos envolvidos, uma vez que foi preciso adaptar as atividades às características da turma e às necessidades da escola, algo muito recorrente e normal no exercício da docência.

Durante a aplicação do projeto, as bolsistas foram confrontadas ainda com limitações estruturais próprias da escola pública que não oferece, em muitos casos, condições satisfatórias para o melhor desenvolvimento das atividades pedagógicas. Aparelhos de data show quebrados, caixa de som que não funcionava direito, sala de vídeo que não impedia a luminosidade, sinal wifi que não chegava à sala de aula, enfim, inúmeros problemas, que não cabe aos professores solucionar sozinhos, mas ainda assim é preciso driblá-los e acreditar na eficácia da diversificação das metodologias em sala de aula.

O objetivo do Programa Institucional de Bolsas de Iniciação à Docência- PIBID, como referido, tem por meta promover a inserção do licenciando na realidade da escola pública, o que, pode-se afirmar, foi alcançado, uma vez que, durante a realização desse projeto, segundo relato das bolsistas, vivenciaram-se inúmeros problemas e foram sentidas muitas frustrações, mas, em contrapartida, criou-se vínculo com os adolescentes e se notaram mudanças no comportamento delas e dos alunos e no funcionamento da própria escola.

O crescimento profissional e pessoal foi imensurável, pois aprender a ser professor é ato contínuo de troca com os discentes e o ambiente escolar, o que constitui a essência e a beleza da profissão.

Dessa experiência, ficou evidente a necessidade de enfrentamento das chamadas questões sensíveis que nada mais são que gargalos impeditivos do pleno exercício da cidadania em nosso país e do papel das ciências humanas nessa tarefa. Não cabe mais a aplicação de conteúdos que expressem conhecimento descolado dos problemas reais e que não contemplem a construção da compreensão dos problemas apresentados, com criticidade e possibilidade de construção de posicionamentos seguros.

O reconhecimento da necessidade de mudança nas práticas em sala de aula e de que qualquer prática pedagógica futura deve priorizar ações educativas metodologicamente bem embasadas e claras na intencionalidade educativa confirma que arranjos e improvisos não condizem com ação pedagógica que intente ser transformadora e significativa.

Reitera-se a importância da escola como lócus fundamental para desenvolver a temática de gênero. Está claro o papel do ambiente escolar nesse processo, pois é nele que se elaboram e reelaboram valores e crenças e se opera sua problematização. Especificamente, a utilidade do conhecimento histórico para promover a discussão de processos de inferiorização de mais 
variada natureza e reverter tais condições pela mudança do olhar e do sentir essas questões. A escola foi valorizada como meio potencializador para o desenvolvimento de conteúdos, que, embora não percebidos dessa forma, atravessam a experiência individual e de grupo e conduzem à construção de consciências sociais, muito necessárias ao país e seu projeto de sociedade.

Assim, o sistema educacional vem pedindo educadores atentos às relações pessoais e às questões de seu cotidiano, com capacidade de se relacionar com seus alunos, com a sensibilidade para observar e perceber as mais diversificadas realidades e, principalmente, comprometido, política e socialmente, com a transformação da sociedade em que vive.

\section{Referências}

ABRAMOWICZ, Anete; RODRIGUES, Tatiane Consentino; CRUZ, Ana Cristina Juvenal da A diferença e a diversidade na educação. Contemporânea, São Carlos, n. 2, p. 85-97, ago./dez. 2011.

http://www.contemporanea.ufscar.br/index.php/contemporanea/article/view/38.

AGUIAR, Neuma (org.). Gênero e ciências humanas: desafio às ciências desde a perspectiva das mulheres. Rio de Janeiro: Rosa dos Tempos, 1997.

AKOTIRENE, Carla. Interseccionalidade. Belo Horizonte: Letramento, 2018.

ARRAES, Jarid. As lendas de Dandara. Porto Alegre: Livre, 2015.

BOTÃO, Isabel Cristina; LOPES, Fernanda; FÉLIX, Jeane; VIEIRA, Nara. Gêneros: adolescentes e jovens para a educação entre pares. Saúde e prevenção nas escolas. 1. ed. Brasília: Ministério da Saúde, 2010.

BOURDIEU, Pierre. A dominação masculina. 4. ed. Rio de Janeiro: Bertrand Brasil, 2005.

BRASIL. Ministério da Educação. Coordenação de Aperfeiçoamento de Pessoal de Nível Superior-CAPES. Portaria n. 096, de 18 de julho de 2013. Brasília: CAPES, 2013. Disponível em:

https://capes.gov.br/images/stories/download/legislacao/Portaria_096_18jul13_AprovaRegulame ntoPIBID.pdf.

BRASIL. Decreto n. 7.219, de 24 de junho de 2010. Dispõe sobre o Programa Institucional de Bolsa de Iniciação à Docência - PIBID e dá outras providências. Diário Oficial da União: seção 1, Brasília, DF, p. 4, 25 jun. 2010. Disponível em: https://www.planalto.gov.br/ccivil_03/_ato2007-2010/2010/decreto/d7219.htm.

BRASIL. Ministério da Educação. Secretaria de Educação Fundamental. Parâmetros Curriculares Nacioniais: temas transversais/orientação sexual. Brasília: MEC; SEF, 1998. v. 10.5. Disponível em: http://basenacionalcomum.mec.gov.br/images/pcn/orientacao.pdf.

CARDOSO, Ciro Flamarion S. O Egito Antigo. São Paulo: Brasiliense, 1982.

CARIA, Thamis Malena Marciano. Aspectos da condição feminina no Antigo Egito. Revista Mundo Antigo, Campos dos Goytacases, ano II, v. 2, n. 1, p. 93-106, jun. 2013. Disponível em: http://www.nehmaat.uff.br/revista/2013-1/artigo04-2013-1.pdf. 
CARNEIRO, Valnêda; CAVALCANTI, Vanessa R. S. (org.). Direitos humanos: múltiplos olhares. Salvador: Romanegra, 2012.

CARVALHO, Maria Eulina Pessoa de; RABAY, Glória; BRADO, Tania Suely Antonelli Marcelino; FÉLIX, Jeane; DIAS, Alfrancio Ferreira. Direitos humanos das mulheres e das pessoas LGBTQI: inclusão da diversidade sexual e de gênero na educação e na formação docente. João Pessoa: EDUFPB, 2017.

CASTRO, Eliana de Moura; MACHADO, Marília Novais da Mata. Muito bem, Carolina! Biografia de Carolina Maria de Jesus. Belo Horizonte: C/Arte, 2007.

CHARTIER, Roger. Diferenças entre os sexos e dominação simbólica (nota crítica). Cadernos Pagu, Campinas, n. 4, p. 37-47, 1995. Disponível em: https://periodicos.sbu.unicamp.br/ojs/index.php/cadpagu/article/view/1761/1816.

FÓRUM BRASILEIRO DE SEGURANÇA PÚBLICA - FBSP. Anuário brasileiro de segurança pública 2019. São Paulo: FBSP, 2019. Disponível em: http://www.forumseguranca.org.br/wp-content/uploads/2019/09/Anuario-2019FINAL-v3.pdf. Acesso em: 13 jun. 2020.

FREIRE, Paulo. Pedagogia do oprimido. Rio de Janeiro: Paz e Terra, 2005.

FURTADO, Júnia. Chica da Silva e o contratador de diamantes: o outro lado do mito. São Paulo: Companhia das Letras, 2003.

GIMENO SACRISTÁN, José. Poderes instáveis em educação. Tradução: Beatriz Affonso Neves. Porto Alegre: Artes Médicas Sul, 1999.

HERNÁNDEZ, Fernando; VENTURA, Montserrat. A organização do currículo por projetos de trabalho: o conhecimento é um caleidoscópio. 5. ed. Porto Alegre: Artmed, 1998.

INSTITUTO DE PESQUISA ECONÔMICA APLICADA - IPEA; FÓRUM BRASILEIRO DE SEGURANÇA PÚBLICA - FBSP. Atlas da violência 2019. Brasília: IPEA; FBSP, 2019. Disponível em: https://www.ipea.gov.br/atlasviolencia/arquivos/downloads/6537-atlas2019.pdf. Acesso em :13 jun. 2020.

MATA, Giselle Moreira da. "Entre risos e lágrimas": uma análise das personagens femininas atenienses na obra de Aristófanes (séculos VI a IV A.C.). 2009. 222 f. Dissertação (Mestrado em História) - Faculdade de História, Universidade Federal de Mato Grosso, Goiânia, 2009.

MEDEIROS, Luiz Gonzaga Bezerra; QUEIROGA, Maria do Socorro Nascimento; CARVALHO, Maria Elizete G. (org.). Educação e direitos humanos: interfaces. João Pessoa: Editora da UFPB, 2012.

MONTEIRO, Ana Maria. Tempo presente no ensino de história: o anacronismo em questão In: GONÇALVES, Márcia de Almeida; ROCHA, Helenice; REZNIK, Luís; MONTEIRO, Ana Maria (org.). Qual o valor da história hoje? Rio de Janeiro: FGV, 2012. p. 191-214.

ONU MUJERES. Oficina del Alto Comisionado de las Naciones Unidas para los Derechos Humanos. Modelo de protocolo latinoamericano de investigación de las muertes violentas de mujeres por razones de género 2014. Ciudad de Panamá: ONU; OACNUDH, 2014. Disponível em:

https://www.ohchr.org/Documents/Issues/Women/WRGS/ProtocoloLatinoamericanoDeInvestig acion.pdf . Acesso em 13 de novembro. de 2018.

ONU MULHERES. Secretaria de Políticas para Mulheres. Diretrizes nacionais para investigar, processar e julgar com perspectiva de gênero as mortes violentas de mulheres (feminicídios). 
Formação Docente e Ensino de História: violência contra as mulheres e sua luta por direitos como tema de experiência didático-pedagógica em sala de aula - Edna Maria Matos Antonio; Fernanda Carolina Pereira dos Santos

Brasília: ONU; SPM, 2016. Disponível em: https://oig.cepal.org /sites/default/files/diretrizes_para_investigar_processar_e_julgar_com_perspectiva_de_genero_a s_mortes_violentas_de_mulheres.pdf. Acesso em: 15 ago. 2016.

PEDRO, Joana Maria. Relações de gênero como categoria transversal na historiografia contemporânea. Topoi, Rio de Janeiro, v. 12, n. 22, p. 270-283, jan./jun. 2011. Disponível em: https://www.scielo.br/pdf/topoi/v12n22/1518-3319-topoi-12-22-00270.pdf.

PEDRO, Joana Maria. Traduzindo o debate: o uso da categoria de gênero na pesquisa histórica. Revista História, São Paulo, v. 24, n. 1, p. 77-98, 2005. Disponível em: https://www.scielo.br/pdf/his/v24n1/a04v24n1.pdf.

PEREIRA, Hélder Moura. Poemas de amor do antigo Egipto. Tradução: Hélder Moura Pereira. Introdução: Paulo da Costa Domingos. Lisboa: Assírio \& Alvim, 1998.

PERROT, Michelle. A mulher popular rebelde. In: PERROT, Michelle. Os excluídos da história: operários, mulheres e prisioneiros. Tradução: Denise Bottmann. Rio de Janeiro: Paz e Terra, 1988.

PRATAS, Glória Maria D. L. Trabalho e religião: o papel da mulher na sociedade faraônica. Revista Mandrágora, São Paulo, v. 17, n. 17, p. 157-173, 2011. Disponível em: https://www.metodista.br/revistas/revistas-ims/index.php/MA/article/view/2752/2938.

REIS, José Carlos. As identidades do Brasil: de Varnhagen a FHC. Rio de Janeiro: Editora FGV, 1999.

REYES, Jose Carlos Castaneda. Señoras y esclavas: el papel de la mujer en la historia social del Egipto antiguo. México: Colégio de México, 2008.

RÜSEN, Jörn. História viva: teoria da história. Formas e funções do conhecimento histórico. Tradução: Estevão de Rezende Martins. Brasília: Editora UNB, 2007.

SCOTT, Joan. Gênero: uma categoria útil de análise histórica. Educação e Realidade, Porto Alegre, v. 15, n. 2, p. 71-97, jul./dez. 1995. Disponível em: https://seer.ufrgs.br/educacaoerealidade/article/view/71721/40667.

SILVA, Cristiani Bereta da. O saber histórico escolar sobre as mulheres e relações de gênero nos livros didáticos de história. Caderno Espaço Feminino, v. 17, n. 1, p. 219-246, jan./jul. 2007. Disponível em: http://www.seer.ufu.br/index.php/neguem/article/view/440. Acesso em: 4 out. 2017.

SILVA, Cristiani Bereta da; ROSSATO, Luciana; OLIVEIRA, Núcia Alexandra Silva de. Formação docente em história: igualdade de gênero e diversidade. Revista Retratos da Escola, Brasília, v. 7, n. 13, p. 453-465, jul./dez. 2013. Disponível em: http//www.esforce.org.br. Acesso em: 11 out. 2017.

SOIHET, Rachel. Violência simbólica: saberes masculinos e representações femininas. Revista Estudos Feministas, Florianópolis, v. 5, n. 1, 1997. Disponível em: https://periodicos.ufsc.br/index.php/ref/article/view/12558/11703.

SOIHET, Rachel; PEDRO, Joana Maria. A emergência da pesquisa da história das mulheres e das relações de gênero. Revista Brasileira de História, São Paulo, v. 27, n. 54, p. 281-300, 2007. Disponível em: https://www.scielo.br/pdf/rbh/v27n54/a15v2754.pdf.

TARDIF, M. Saberes docentes e formação profissional. 7. ed. Petrópolis, RJ: Vozes, 2002. 